\title{
Influence of Hyperhomocysteinemia on the Cellular Redox State - Impact on Homocysteine-Induced Endothelial Dysfunction
}

\author{
Norbert Weiss ${ }^{1 *}$, Stanley J. Heydrick², Otilia Postea1, \\ Christiane Keller ${ }^{1}$, John F. Keaney Jr. ${ }^{2}$ and \\ Joseph Loscalzo² \\ 1 Medizinische Poliklinik - Innenstadt, Klinikum der \\ Universität München, Munich, Germany \\ 2 Whitaker Cardiovascular Institute, Boston University School \\ of Medicine, Boston, MA, USA
}

Hyperhomocysteinemia is an independent risk factor for the development of atherosclerosis. An increasing body of evidence has implicated oxidative stress as being contributory to homocysteine's deleterious effects on the vasculature. Elevated levels of homocysteine may lead to increased generation of superoxide by a biochemical mechanism involving nitric oxide synthase, and, to a lesser extent, by an increase in the chemical oxidation of homocysteine and other aminothiols in the circulation. The resultant increase in superoxide levels is further amplified by homocysteinedependent alterations in the function of cellular antioxidant enzymes such as cellular glutathione peroxidase or extracellular superoxide dismutase. One direct clinical consequence of elevated vascular superoxide levels is the inactivation of the vasorelaxant messenger nitric oxide, leading to endothelial dysfunction. Scavenging of superoxide anion by either superoxide dismutase or 4,5-dihydroxybenzene 1,3-disulfonate (Tiron) reverses endothelial dysfunction in hyperhomocysteinemic animal models and in isolated aortic rings incubated with homocysteine. Similarly, homocysteine-induced endothelial dysfunction is also reversed by increasing the concentration of the endogenous antioxidant glutathione or overexpressing cellular glutathione peroxidase in animal models of mild hyperhomocysteinemia. Taken together, these findings strongly suggest that the adverse vascular effects of homocysteine are at least partly mediated by oxidative inactivation of nitric oxide. Clin Chem Lab Med 2003; 41(11):1455-1461

Key words: Homocysteine; Oxidant stress; Nitric oxide; Endothelial dysfunction.

Abbreviations: $\mathrm{CBS}^{(-/+)}$, heterozygous cystathionine $\beta$-synthase-deficient mice; DCF, 2',7'-dichlorofluoresceine; eNOS, endothelial nitric oxide synthase; GPx-1, cellular isoform of glutathione peroxidase; L-NAME, Lnitroarginine methyl ester; NO, nitric oxide; TBARs, thiobarbituric acid reactive substances.

\footnotetext{
*E-mail of the corresponding author:

Norbert.Weiss@med.uni-muenchen.de
}

Introduction

Elevated plasma levels of homocysteine (hyperhomocysteinemia) have been established as a risk factor for atherothrombotic vascular disease during the last two decades. The pathobiological mechanisms by which homocysteine promotes atherothrombosis are not completely understood as yet. One well-supported but not universally accepted hypothesis suggests that hyperhomocysteinemia leads to increased oxidant stress in the vasculature. This effect may be central to its promotion of vascular pathology, partly by decreasing the bioavailability of the endothelial antiatherogenic signalling molecule nitric oxide. The resulting endothelial dysfunction is contributory to decreased vasodilator capacity, activation of circulating leukocytes and platelets, activation of prothrombotic and inhibition of fibrinolytic mechanisms, and stimulation of vascular smooth muscle cell proliferation. All these effects participate in the initiation and progression of atherosclerotic lesions and thrombus formation (1). The purpose of this article is to review recent advances in understanding the mechanisms by which elevated levels of homocysteine induce vascular oxidant stress, and the impact of such stress on endothelial function in the clinical setting.

Hyperhomocysteinemia Is Associated with Increased Superoxide Output

Experiments in hyperhomocysteinemic animals and incubation of cultured endothelial cells with homocysteine indicate that elevated levels of homocysteine lead to increased formation of reactive oxygen species. Aortic tissue from mildly hyperhomocysteinemic heterozygous cystathionine $\beta$-synthase-deficient $\left(\mathrm{CBS}^{-/+}\right.$) mice produces more superoxide anion compared to wildtype mice (2), as measured by the lucigenin chemiluminescence assay or the cytochrome c assay. The same effect could be demonstrated in cultured endothelial cells incubated with homocysteine (3). This enhanced superoxide formation seems to be a critical determinant of homocysteine-induced endothelial dysfunction as scavenging of superoxide anion by either superoxide dismutase or 4,5-dihydroxybenzene 1,3 disulfonate (Tiron) has been shown to reverse endothelial dysfunction in hyperhomocysteinemic animal models $(2,4)$ and in isolated aortic rings incubated with homocysteine (3).

Superoxide anion reacts with nitric oxide in a diffusion-limited reaction to form peroxynitrite (5), which does not induce vasorelaxation (6), and is itself highly 

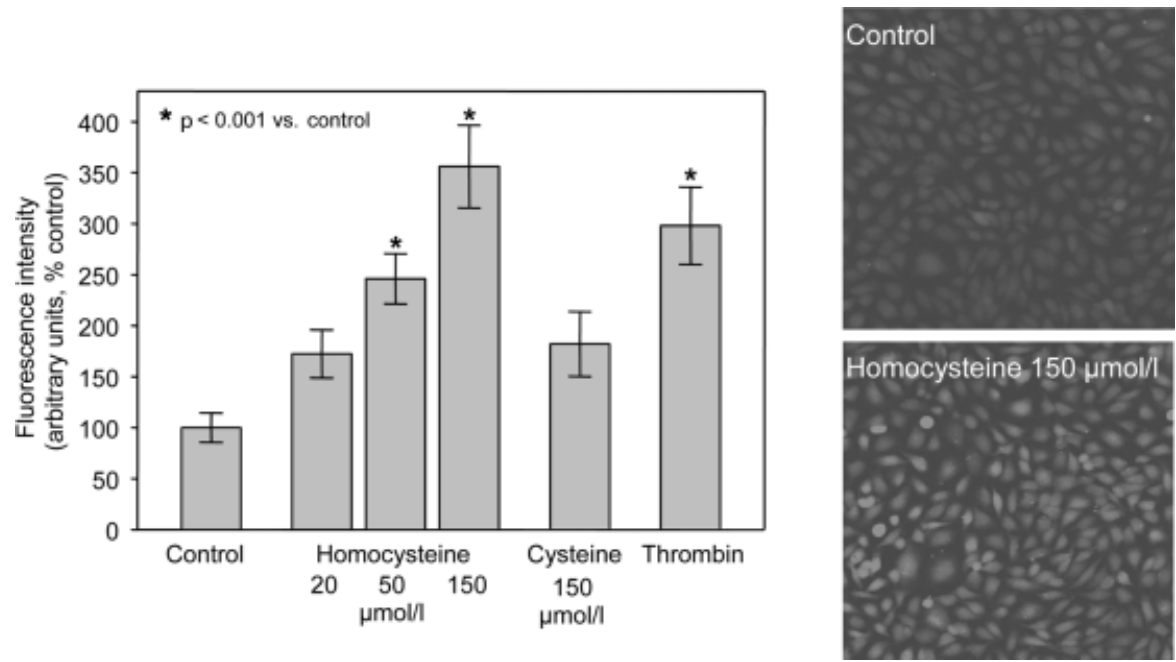

Figure 1 Homocysteine dose-dependently increases the fluorescence of the reactive oxygen species-sensitive dye DCF in cultured endothelial cells. EA-Hy 926 cells were loaded with dichloroflurosceine-diacetate and incubated with different concentrations of homocysteine and cysteine, respectively, for 6 hours. Thrombin was used as a positive control. Intracel- lular DCF-fluorescence was visualized using confocal laser microscopy and quantified by image analysis. The left panel shows the mean \pm SEM fluorescence intensity of four experiments, and the right panel shows representative fluorescence-microscopy images. reactive. The potential physiological relevance of this reaction is demonstrated by immunohistochemical and immunoblot data showing an increase in protein tyrosine nitration, a marker of peroxynitrite-dependent protein oxidation, in vascular tissues from mildly hyperhomocysteinemic mice (2), and in lysates from aortic rings cultured in homocysteine-containing media (7).

The role of hydrogen peroxide, which is produced from superoxide via superoxide dismutase, in homocysteine-induced endothelial toxicity in vitro is somewhat more nebulous. Early studies demonstrated that catalase inhibits the homocysteine-induced lysis of endothelial cells in the presence of transition metals or ceruloplasmin $(8,9)$, but this lytic effect of homocysteine was only observed at concentrations far exceeding those observed in the most severe cases of hyperhomocysteinemia. More recently, we (Figure 1) and others (10-12) have observed a homocysteine dosedependent increase in the fluorescence of an hydrogen peroxide-sensitive fluorescent probe, $2^{\prime}, 7^{\prime}$-dichlorofluoresceine (DCF), in cultured endothelial cells, but the interpretation of these results is tempered by the observation that DCF also fluoresces when it reacts with peroxynitrite and reactive oxygen species other than hydrogen peroxide.

\section{Mechanisms of Increased Vascular Oxidant Stress in Hyperhomocysteinemia}

\section{Elevation of the oxidation rate of homocysteine in hyperhomocysteinemia}

Homocysteine is an intermediate in the methionine cycle, the function of which is to generate one-carbon methyl groups in the form of S-adenosylmethionine for transmethylation reactions (13). The essential amino acid methionine is the precursor of homocysteine. In mammals, homocysteine can be diverted from the methionine cycle into the transsulfuration pathway to generate the non-essential amino acid cysteine, or it can be remethylated to methionine. Chemically, methionine contains a sulfide sulfur (R-S- $\left.\mathrm{R}^{\prime}\right)$, whereas homocysteine and cysteine are sulfhydryl compounds (R-SH). Compounds containing a free sulfhydryl group are known as "thiols." Other biologically relevant low-molecular-weight thiols are glutathione, coenzyme A, and dihydrolipoic acid. Under aerobic conditions (i.e., in the presence of molecular oxygen as an electron acceptor) and at physiological $\mathrm{pH}$, thiols such as homocysteine, oxidize to form disulfides, according to the general reaction $2 \mathrm{RSH}+\mathrm{O}_{2} \Leftrightarrow \mathrm{RSSR}+\mathrm{H}_{2} \mathrm{O}_{2}$. In plasma, this reaction can be catalyzed by transition metals such as copper and cobalt (the former present in the circulation associated with albumin and ceruloplasmin, the latter with cobalamin). Homocysteine has classically been thought to autooxidize readily via this mechanism to form homocystine, oxidize other thiols such as cysteine and glutathione to form mixed disulfides, or oxidize free cysteine residues on proteins and peptides to form mixed disulfides (Figure 2). This notion is supported by the observation that $1 \%$ or less of total homocysteine species consists of free homocysteine in the plasma of healthy humans under physiological conditions, whereas $5-15 \%$ consist of homocystine, another $5-15 \%$ are mixed disulfides (cysteine-homocysteine or glutathione-homocysteine), and more than $70 \%$ are protein-bound (14). Moreover, a decreased ratio of reduced to total aminothiols in plasma has been demonstrated in experimental hyperhomocysteinemia after a methionine challenge (14-16) and in hyperhomocysteinemic patients $(17-20)$. More recent evi- 
<smiles>[NH3+]C(CCS)C(=O)[O-]</smiles>

Homocysteine MW 135.19<smiles>[NH3+]C(CCSSCCC([NH3+])C(=O)[O-])C(=O)[O-]</smiles>

Homocystine MW 268.36<smiles>[NH3+]C(CCSSCC([NH3+])C(=O)[O-])C(=O)[O-]</smiles>

Homocysteine-cysteine mixed disulfide MW 254.33<smiles>CC(CSSCCC([NH3+])C(=O)[O-])(NC(=O)CCC([NH3+])C(=O)[O-])C(=O)NCC(=O)[O-]</smiles>

Homocysteine-glutathione mixed disulfide MW 439.49<smiles>[NH3+]C(CCSSC1CCCCC1)C(=O)[O-]</smiles>

Protein-bound homocysteine

Figure 2 Chemistry of homocysteine and different homocysteine oxidation products.

dence, however, suggests that oxidized forms of homocysteine in plasma arise primarily via disulfide exchange, with only a small fraction resulting from direct homocysteine oxidation (21). Hence, the contribution of direct homocysteine oxidation to homocysteine-induced vascular oxidative stress may not be as important as enzymatic mechanisms.

Involvement of nitric oxide synthase in the generation of reactive oxygen species

Recent in vitro experiments (SH, NW, JL, JK, unpublished observations) suggest that homocysteine-in- duced oxidant stress is stereospecific for the naturally occuring L-isoform, indicating a biochemical rather than chemical basis for the effect. In these experiments, increased lipid peroxidation was observed in endothelial cells incubated with L-homocysteine, but not with D-homocysteine, as measured by total isoprostane $\mathrm{F}_{2 \alpha}$-III and thiobarbituric acid reactive substances (TBARs) levels in the supernatant of endothelial cell cultures. Stereospecificity was also observed for DCF fluorescence in situ, indicating a parallel effect on overall reactive oxygen species content. Enhanced lipid peroxidation and DCF-fluorescence was not observed with either cysteine or glutathione, and was not due to extracellular thiol oxidation, as it could be fully replicated with the oxidized disulfide form of homocysteine, L-homocystine.

Mechanistically, this pro-oxidant effect seems to be dependent upon both endothelial nitric oxide synthase and superoxide anion. Pharmacological inhibition of endothelial nitric oxide synthase with L-nitroarginine methyl ester (L-NAME) completely blocked the homocysteine-dependent stimulation of reactive oxygen species formation as measured by DCF-fluorescence. Furthermore, L-NAME completely abrogated both the homocysteine-dependent increases in isoprostane $\mathrm{F}_{2 \alpha}$-III formation and DCF fluorescence. Similarly, transfection of endothelial cells with superoxide dismutase cDNA blocked the effect of homocysteine on endothelial cell lipid peroxidation, whereas addition of extracellular superoxide dismutase had no effect. Importantly, neither the addition of extracellular catalase nor loading cells with catalase had any effect on lipid peroxidation, indicating that hydrogen peroxide is not involved in this process.

The most straightforward explanation for these results would be that homocysteine induces increased

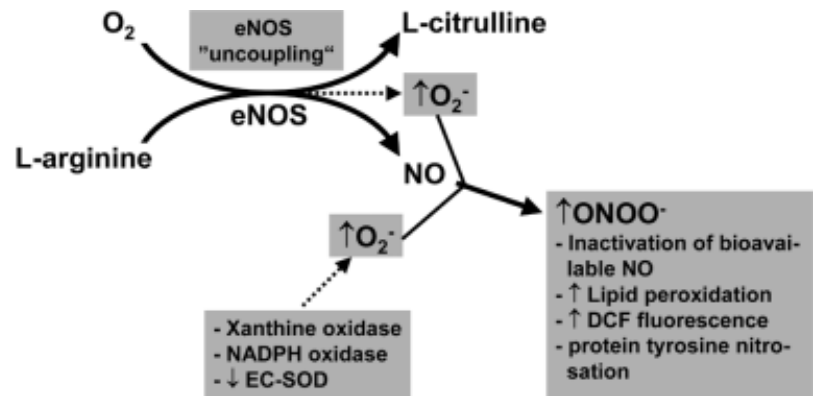

Figure 3 Hypothetical mechanism of nitric oxide synthasedependent generation of reactive oxygen species in hyperhomocysteinemia. L-homocysteine and L-homocystine, but not the respective $D$-isoforms, increase membrane lipid peroxidation and DCF-fluorescence in cultured endothelial cells. This effect is dependent on endothelial nitric oxide synthase (eNOS) and superoxide anion $\left(\mathrm{O}_{2}^{-}\right)$, as L-NAME and transfection of endothelial cells with superoxide dismutase cDNA, respectively, block homocysteine's effects. Increased $\mathrm{O}_{2}^{-}$may result from "uncoupling" of eNOS and/or from other enzymatic sources. Some of the excess $\mathrm{O}_{2}{ }^{-}$reacts with nitric oxide (NO) to form peroxynitrite (ONOO-). This reaction leads to biological inactivation of NO. Furthermore, ONOO- initiates lipid peroxidation and increases DCF-fluorescence. 
formation of peroxynitrite. Unlike superoxide, peroxynitrite is both able to initiate lipid peroxidation (22) and to react with DCF (23). Peroxynitrite has a short halflife, which makes its detection difficult in biological systems (24), but may react with cellular tyrosine residues to form nitrosated endproducts. As mentioned earlier, immunostaining for one such endproduct, 3-nitrotyrosine, was positive in aortic tissue from mildly hyperhomocysteinemic $\mathrm{CBS}^{(-/+)}$mice compared with wild-type mice (2), as was an immunoblot analysis for 3-nitrotyrosine of protein lysates from aortic rings cultured in homocysteine-containing media (7).

Although the precise mechanism by which homocysteine may induce increased peroxynitrite formation remains to be elucidated, two potential mechanisms include endothelial nitric oxide synthase "uncoupling" $(5,25)$, in which endothelial nitric oxide synthase is the source of superoxide (and peroxynitrite); and increased superoxide production from other enzymatic sources, in which some of the excess superoxide reacts with nitric oxide to form peroxynitrite (Figure 3).

\section{Inhibition of cellular antioxidant enzymes by homocysteine}

The cellular defense system against reactive oxygen species includes several antioxidant enzymes (Figure 4) and non-enzymatic antioxidants, such as $\alpha$-tocopherol, ascorbic acid, $\beta$-carotene, and glutathione. Homocysteine has been shown in particular to disrupt the normal function of two important cellular antioxidant enzymes, the cellular isoform of glutathione peroxidase (GPX-1) and superoxide dismutase.

Homocysteine, but not other low-molecular-weight thiols, decreases both the expression and specific activity of GPx-1 as shown in vitro and in vivo (26-31). This key enzyme for the cellular defense against oxidant stress uses glutathione to reduce hydrogen peroxide and lipid peroxides to their respective alcohols (32), and may also act as a peroxynitrite reductase (33). Transition metal ions such as iron and copper catalyze the breakdown of hydrogen peroxide to form hydroxyl radical $(\cdot \mathrm{OH})$, which is highly reactive and causes lipid peroxidation, among its numerous effects; and hydroxide anion $\left(\mathrm{OH}^{-}\right)$, which promotes alkaline tissue damage. This process is offset in part by catalase and GPx-1-dependent reduction of $\mathrm{H}_{2} \mathrm{O}_{2}$ to $\mathrm{H}_{2} \mathrm{O}$. Elevated levels of lipid peroxides are accompanied by an increase in peroxyl radicals, which can inactivate nitric oxide through the formation of lipid peroxynitrites $(34,35)$. Thus a deficiency of GPx-1 may lead to a decrease in bioavailable nitric oxide via at least two mechanisms, an increase in

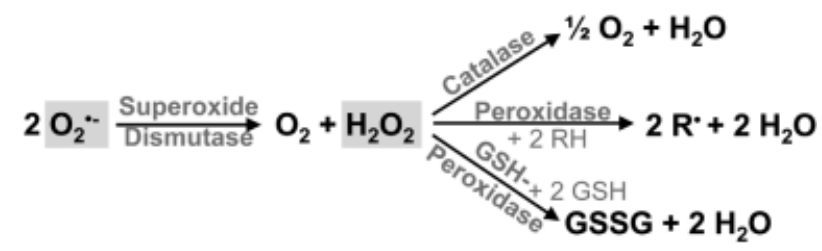

Figure 4 Enzymatic inactivation of reactive oxygen species. reactive oxygen species and an increase in lipid hydroperoxides. In support of this hypothesis we have shown previously that mice deficient in GPx-1 have endothelial dysfunction owing to decreased bioavailable endothelium-derived nitric oxide; increased oxidative stress and increased lipid hydroperoxide generation as measured by increased tissue isoprostane $F_{2 \alpha}-1 I I$ and hepatic phospholipid hydroperoxide levels; and increased nitrosative stress, as indicated by increased immunostaining for 3-nitrotyrosine in aortic tissue of GPX-1 knockout mice compared to wild-type mice (36).

Extracellular superoxide dismutase is a secreted glycoprotein with an affinity for heparin-like glycosaminoglycans. It is present in the circulation in equilibrium between the glycosaminoglycans on the endothelial surface and the plasma phase, and acts as the principal enzymatic scavenger of superoxide in the extracellular space $(37,38)$. The plasma levels of extracellular superoxide dismutase correlate positively with plasma homocysteine levels in homocystinuric patients (39) and in patients with mild hyperhomocysteinemia (40). This effect is caused by decreased binding of extracellular superoxide dismutase to endothelial cell surfaces by alterations in the endothelial heparan sulfate proteoglycan by homocysteine (41). This effect may result in a loss of the ability to protect the endothelial surface from oxidative stress, although this hypothesis has not yet been definitively proven.

In summary, experimental data suggest that elevated levels of homocysteine lead to increased vascular generation of reactive oxygen species, primarily by a mechanism involving nitric oxide synthase, and secondarily due to increased homocysteine oxidation. These effects are further amplified by alterations in the function of important cellular antioxidant enzymes. The resultant vascular oxidant stress may lead to vascular dysfunction.

\section{Impact of Increased Vascular Oxidant Stress on Homocysteine-Induced Endothelial Dysfunction}

Endothelial dysfunction, which can be defined in part as an impairment of endothelium-dependent vasoreactivity and regulation of blood flow in the presence of normal endothelium-independent vasodilation, appears to be a key event in homocysteine-induced vascular pathobiology (1). Endothelial dysfunction has been demonstrated in several different animal models of mild hyperhomocysteinemia, including hyperhomocysteinemia induced by vitamin-deficient and methionine-enriched diets in cynomolgus monkeys (42) or rats $(43,44)$, by heterozygous disruption of the cystathionine $\beta$-synthase gene in mice (CBS ${ }^{(-+)}$mice) $(2,30,31)$, or by the combination of genetic and dietary manipulation (45). Endothelial dysfunction has also been demonstrated in healthy humans with either acutely elevated plasma homocysteine levels following an oral methionine challenge (46-56) or with chronic, mild hyperhomocysteinemia (57-59).

In these studies, homocysteine impaired endothe- 
lium-dependent vasodilator function induced by shear stress, acetylcholine, or bradykinin, but did not affect endothelium-independent vasodilation induced by sodium nitroprusside or nitroglycerin. These findings indicate that the effects of homocysteine are due, at least in part, to a decrease in endogenous bioavailable nitric oxide. This conclusion is supported by the observation that the accumulation of cyclic guanosine monophosphate, the second messenger of nitric oxide-mediated vasodilation, was decreased in aortas from mildly hyperhomocysteinemic CBS ${ }^{(-+)}$mice compared to their wild-type littermates (2), and that the plasma levels of the nitric oxide-derived endproducts nitrite and nitrate were significantly lower in hyperhomocysteinemic subjects than in healthy controls (59). In accordance with these in vivo findings, homocysteine, but not cysteine, has been shown to decrease the production and/or bioactivity of nitric oxide and of S-nitrosothiols by cultured endothelial cells $(11,26,30)$.

The link between vascular oxidant stress and the development of homocysteine-mediated vascular pathobiology has been established in in vivo studies in which homocysteine-induced endothelial dysfunction was reversed by increasing cellular antioxidant capacity. Treatment of hyperhomocysteinemic CBS ${ }^{(-/)}$mice with the intracellular cysteine donor L-2-oxo-4-thiazolidine carboxylate, an agent that increases intracellular levels of reduced glutathione and total thiols and thereby shifts the cellular redox state to a more reduced environment, restores endothelial function (31). Restoration of normal endothelial function in hyperhomocysteinemic $\mathrm{CBS}^{(-/+)}$mice could also be achieved by overexpression of cellular glutathione peroxidase (30). This effect might be due to decreased oxidative inactivation of nitric oxide, as overexpression of cellular glutathione peroxidase in cultured endothelial cells has been shown to attenuate the homocysteine-induced decrease in nitric oxide release from these cells (30). Further support for the link between homocysteine-dependent endothelial dysfunction and oxidative stress has been established in clinical studies demonstrating that treatment with antioxidant vitamins prevents endothelial and platelet dysfunction associated with hyperhomocysteinemia induced by oral methionine challenge $(48,50,56,60)$. Taken together, these findings suggest that the adverse vascular effects of homocysteine are at least partly mediated by oxidative inactivation of nitric oxide.

\section{Potential Clinical Consequences}

Several clinical studies, including 12 randomized and placebo-controlled intervention trials, have shown that supplementation with folic acid, vitamin $B_{6}$, and vitamin $B_{12}$ lowers plasma homocysteine levels in most patients (61). The reduction in plasma homocysteine levels leads to normalization of endothelial function (62-65). Whether or not this translates into a reduction in cardiovascular morbidity and mortality is currently under investigation in several intervention studies.
Plasma homocysteine levels cannot, however, be normalized by vitamin supplementation in all cases. For example, hyperhomocysteinemia persists even with folic acid treatment ( $1-5 \mathrm{mg} /$ day) in many patients with chronic renal failure (66). Alternative therapeutic options directed at reducing the cardiovascular risk associated with hyperhomocysteinemia are warranted in these subgroups of patients. Antioxidant therapy seems to be one such strategy. In this context it is worth mentioning that, although the results of trials of antioxidants for reducing cardiovascular morbidity and mortality in the general population were disappointing and did not show a benefit (67), there are two clinical trials in patients with chronic renal failure that showed a significant benefit of $\alpha$-tocopherol or the thiol antioxidant $\mathrm{N}$-acetylcysteine on cardiovascular morbidity and mortality $(68,69)$. Whether or not this relates to an effect of antioxidants on improving homocysteine-induced endothelial dysfunction in patients with chronic renal failure remains to be determined. Nevertheless the experimental data reviewed here and the results of these two clinical trials encourage further evaluation of the effect of antioxidant strategies in selected groups of patients at risk of cardiovascular disease, as in patients with hyperhomocysteinemia who do not respond to folic acid supplementation.

\section{Acknowledgements}

Supported by grants from the Deutsche Forschungsgemeinschaft (WE 1984/2-1) to N.W. and from the National Institutes of Health (HL55993, HL58976, HL61828, and HV28178) to J.L.

\section{References}

1. Weiss N, Keller C, Hoffmann U, Losclazo J. Endothelial dysfunction and atherothrombosis in mild hyperhomocysteinemia. Vasc Med 2002; 7:227-39.

2. Eberhardt RT, Forgione MA, Cap A, Leopold JA, Rudd MA, Trolliet $\mathrm{M}$, et al. Endothelial dysfunction in a murine model of mild hyperhomocyst(e)inemia. J Clin Invest 2000; 106:483-91.

3. Lang D, Kredan MB, Moat SJ, Hussain SA, Powell CA, Bellamy MF, et al. Homocysteine-induced inhibition of endothelium-dependent relaxation in rabbit aorta: role for superoxide anions. Arterioscler Thromb Vasc Biol 2000; 20:422-7.

4. Zhang F, Slungaard A, Vercellotti GM, ladecola C. Superoxide-dependent cerebrovascular effects of homocysteine. Am J Physiol 1998; 274:R1704-11.

5. Pritchard KA Jr, Groszek L, Smalley DM, Sessa WC, Wu M, Villalon $\mathrm{P}$, et al. Native low-density lipoprotein increases endothelial cell nitric oxide synthase generation of superoxide anion. Circ Res 1995; 77:510-8.

6. Gryglewski RJ, Palmer RM, Moncada S. Superoxide anion is involved in the breakdown of endothelium-derived vascular relaxing factor. Nature $1986 ; 320: 454-6$.

7. Mujumdar VS, Aru GM, Tyagi SC. Induction of oxidative stress by homocyst(e)ine impairs endothelial function. J Cell Biochem 2001; 82:491-500.

8. Wall RT, Harlan JM, Harker LA, Striker GE. Homocysteine-induced endothelial cell injury in vitro: a model for the study of vascular injury. Thromb Res 1980; 18:113-21. 
9. Starkebaum G, Harlan JM. Endothelial cell injury due to copper-catalyzed hydrogen peroxide generation from homocysteine. J Clin Invest 1986; 77:1370-6.

10. Toborek M, Hennig B. Dietary methionine imbalance, endothelial cell dysfunction and atherosclerosis. Nutr Res 1996; 16:1251-66.

11. Zhang X, Li H, Jin H, Ebin Z, Brodsky S, Goligorsky MS. Effects of homocysteine on endothelial nitric oxide production. Am J Physiol Renal Physiol 2000; 279:F671-8.

12. Chern CL, Huang RF, Chen YH, Cheng JT, Liu TZ. Folate deficiency-induced oxidative stress and apoptosis are mediated via homocysteine-dependent overproduction of hydrogen peroxide and enhanced activation of NF-kappaB in human Hep G2 cells. Biomed Pharmacother 2001; 55 : 434-42.

13. Mato JM, Avila MA, Corrales FJ. Biosynthesis of S-adenosylmethionine. In: Carmel R, Jacobsen DW, editors. Homocysteine in health and disease. Cambridge: Cambridge University Press, 2001:47-62.

14. Mansoor MA, Svardal AM, Schneede J, Ueland PM. Dynamic relation between reduced, oxidized, and proteinbound homocysteine and other thiol components in plasma during methionine loading in healthy men. Clin Chem 1992; 38:1316-21.

15. Guttormsen AB, Mansoor AM, Fiskerstrand T, Ueland PM, Refsum $\mathrm{H}$. Kinetics of plasma homocysteine in healthy subjects after peroral homocysteine loading. Clin Chem 1993; 39:1390-7.

16. Mansoor MA, Guttormsen AB, Fiskerstrand T, Refsum $H$, Ueland PM, Svardal AM. Redox status and protein binding of plasma aminothiols during the transient hyperhomocysteinemia that follows homocysteine administration. Clin Chem 1993; 39:980-5.

17. Andersson A, Lindgren A, Hultberg B. Effect of thiol oxidation and thiol export from erythrocytes on determination of redox status of homocysteine and other thiols in plasma from healthy subjects and patients with cerebral infarction. Clin Chem 1995; 41:361-6.

18. Mansoor MA, Ueland PM, Aarsland A, Svardal AM. Redox status and protein binding of plasma homocysteine and other aminothiols in patients with homocystinuria. Metabolism 1993; 42:1481-5.

19. Mansoor MA, Ueland PM, Svardal AM. Redox status and protein binding of plasma homocysteine and other aminothiols in patients with hyperhomocysteinemia due to cobalamin deficiency. Am J Clin Nutr 1994; 59: $631-5$.

20. Mansoor MA, Bergmark C, Svardal AM, Lonning PE, Ueland PM. Redox status and protein binding of plasma homocysteine and other aminothiols in patients with earlyonset peripheral vascular disease. Homocysteine and peripheral vascular disease. Arterioscler Thromb Vasc Biol 1995; 15:232-40.

21. Sengupta S, Wehbe C, Majors AK, Ketterer ME, DiBello PM, Jacobsen DW. Relative roles of albumin and ceruloplasmin in the formation of homocystine, homocysteinecysteine-mixed disulfide, and cystine in circulation. J Biol Chem 2001; 276:46896-904.

22. Radi R, Beckman JS, Bush KM, Freeman BA. Peroxynitriteinduced membrane lipid peroxidation: the cytotoxic potential of superoxide and nitric oxide. Arch Biochem Biophys $1991 ; 288: 481-7$.

23. Possel H, Noack H, Augustin W, Keilhoff G, Wolf G. 2,7-Dihydrodichlorofluorescein diacetate as a fluorescent marker for peroxynitrite formation. FEBS Lett 1997; 416:175-8.

24. Rubbo H, Freeman BA. Nitric oxide regulation of lipid oxidation reactions: formation and analysis of nitrogen-con- taining oxidized lipid derivatives. Methods Enzymol 1996; 269:385-94.

25. Vasquez-Vivar J, Kalyanaraman B, Martasek P. The role of tetrahydrobiopterin in superoxide generation from eNOS: enzymology and physiological implications. Free Radic Res 2003; 37:121-7.

26. Upchurch GR Jr, Welch GN, Fabian AJ, Freedman JE, Johnson JL, Keaney JF Jr, et al. Homocyst(e)ine decreases bioavailable nitric oxide by a mechanism involving glutathione peroxidase. J Biol Chem 1997; 272:17012-7.

27. Outinen PA, Sood SK, Pfeifer SI, Pamidi S, Podor TJ, Li J, et al. Homocysteine-induced endoplasmic reticulum stress and growth arrest leads to specific changes in gene expression in human vascular endothelial cells. Blood 1999; 94:959-67.

28. Weiss N, Zhang Y, Loscalzo J. Homocyst(e)ine impairs cellular glutathione peroxidase expression and promotes endothelial dysfunction in an animal model of hyperhomocyst(e)inemia [abstract]. Circulation 2000; 102:II-238.

29. Huang R-FS, Hsu Y-C, Lin H-L, Yang FL. Folate depletion and elevated plasma homocysteine promote oxidative stress in rat livers. J Nutr 2001; 131:33-8.

30. Weiss N, Zhang YY, Heydrick S, Bierl C, Loscalzo J. Overexpression of cellular glutathione peroxidase rescues homocyst(e)ine-induced endothelial dysfunction. Proc Natl Acad Sci USA 2001; 98:12503-8.

31. Weiss N, Heydrick S, Zhang YY, Bierl C, Cap A, Loscalzo J. Cellular redox state and endothelial dysfunction in mildly hyperhomocysteinemic cystathionine beta-synthase-deficient mice. Arterioscler Thromb Vasc Biol 2002; 22:34-41.

32. Flohé $\mathrm{L}$. The selenoprotein glutathione peroxidase. In: Dolphin D, Poulson R, Avramovic O, editors. Glutathione: chemical, biochemical and medical aspects. New York: John Wiley \& Sons, Inc., 1989:644-731.

33. Sies H, Sharov VS, Klotz LO, Briviba K. Glutathione peroxidase protects against peroxynitrite-mediated oxidations. A new function for selenoproteins as peroxynitrite reductase. J Biol Chem 1997; 272:27812-7.

34. O'Donnell VB, Freeman BA. Interactions between nitric oxide and lipid oxidation pathways: implications for vascular disease. Circ Res 2001; 88:12-21.

35. Rubbo H, Radi R, Trujillo M, Telleri R, Kalyanaraman B, Barnes $\mathrm{S}$, et al. Nitric oxide regulation of superoxide and peroxynitrite-dependent lipid peroxidation. Formation of novel nitrogen-containing oxidized lipid derivatives. J Biol Chem 1994; 269:26066-75.

36. Forgione MA, Weiss N, Heydrick S, Cap A, Klings ES, Bierl $C$, et al. Cellular glutathione peroxidase deficiency and endothelial dysfunction. Am J Physiol Heart Circ Physiol 2002; 282:H1255-61.

37. Karlsson K, Marklund SL. Heparin-induced release of extracellular superoxide dismutase to human blood plasma. Biochem J 1987; 242:55-9.

38. Adachi T, Yamada H, Futenma A, Kato K, Hirano K. Heparininduced release of extracellular-superoxide dismutase form (V) to plasma. J Biochem (Tokyo) 1995; 117:586-90.

39. Wilcken DE, Wang XL, Adachi T, Hara H, Duarte N, Green K, et al. Relationship between homocysteine and superoxide dismutase in homocystinuria: possible relevance to cardiovascular risk. Arterioscler Thromb Vasc Biol 2000; 20: 1199-202.

40. Wang XL, Duarte N, Cai H, Adachi T, Sim AS, Cranney G, et al. Relationship between total plasma homocysteine, polymorphisms of homocysteine metabolism related enzymes, risk factors and coronary artery disease in the Australian hospital-based population. Atherosclerosis 1999; 146:133-40. 
41. Yamamoto M, Hara H, Adachi T. Effects of homocysteine on the binding of extracellular-superoxide dismutase to the endothelial cell surface. FEBS Lett 2000; 486:159-62.

42. Lentz SR, Sobey CG, Piegors DJ, Bhopatkar MY, Faraci FM, Malinow MR, et al. Vascular dysfunction in monkeys with diet-induced hyperhomocyst(e)inemia. J Clin Invest 1996; 98:24-9.

43. Ungvari Z, Pacher P, Rischak K, Szollar L, Koller A. Dysfunction of nitric oxide mediation in isolated rat arterioles with methionine diet-induced hyperhomocysteinemia. Arterioscler Thromb Vasc Biol 1999; 19:1899-904.

44. Bagi Z, Ungvari Z, Szollar L, Koller A. Flow-induced constriction in arterioles of hyperhomocysteinemic rats is due to impaired nitric oxide and enhanced thromboxane $A(2)$ mediation. Arterioscler Thromb Vasc Biol 2001; 21:233-7.

45. Lentz SR, Erger RA, Dayal S, Maeda N, Malinow MR, Heistad DD, et al. Folate dependence of hyperhomocysteinemia and vascular dysfunction in cystathionine beta-synthase-deficient mice. Am J Physiol Heart Circ Physiol 2000; 279:H970-5.

46. Bellamy MF, McDowell IF, Ramsey MW, Brownlee M, Bones C, Newcombe RG, et al. Hyperhomocysteinemia after an oral methionine load acutely impairs endothelial function in healthy adults. Circulation 1998; 98:1848-52.

47. Hanratty CG, McAuley DF, McGurk C, Young IS, Johnston GD. Homocysteine and endothelial vascular function. Lancet 1998; 351:1288-9.

48. Chambers JC, McGregor A, Jean-Marie J, Obeid OA, Kooner JS. Demonstration of rapid onset vascular endothelial dysfunction after hyperhomocysteinemia: an effect reversible with vitamin C therapy. Circulation 1999; 99:1156-60.

49. Chambers JC, Obeid OA, Kooner JS. Physiological increments in plasma homocysteine induce vascular endothelial dysfunction in normal human subjects. Arterioscler Thromb Vasc Biol 1999; 19:2922-7.

50. Kanani PM, Sinkey CA, Browning RL, Allaman M, Knapp HR, Haynes WG. Role of oxidant stress in endothelial dysfunction produced by experimental hyperhomocyst(e)inemia in humans. Circulation 1999; 100:1161-8.

51. Lambert J, van den Berg M, Steyn M, Rauwerda JA, Donker AJ, Stehouwer CD. Familial hyperhomocysteinaemia and endothelium-dependent vasodilatation and arterial distensibility of large arteries. Cardiovasc Res 1999; 42:743-51.

52. Chao CL, Kuo TL, Lee YT. Effects of methionine-induced hyperhomocysteinemia on endothelium-dependent vasodilation and oxidative status in healthy adults. Circulation 2000; 101:485-90.

53. Boger RH, Lentz SR, Bode-Boger SM, Knapp HR, Haynes WG. Elevation of asymmetrical dimethylarginine may mediate endothelial dysfunction during experimental hyperhomocyst(e)inaemia in humans. Clin Sci (Lond) 2001; 100:161-7.

54. Chambers JC, Ueland PM, Wright M, Dore CJ, Refsum H, Kooner JS. Investigation of relationship between reduced, oxidized, and protein-bound homocysteine and vascular endothelial function in healthy human subjects. Circ Res 2001; 89:187-92.

55. Hanratty CG, McGrath LT, McAuley DF, Young IS, Johnston GD. The effects of oral methionine and homocysteine on endothelial function. Heart 2001; 85:326-30.

56. Raghuveer G, Sinkey CA, Chenard C, Stumbo P, Haynes WG. Effect of vitamin $\mathrm{E}$ on resistance vessel endothelial dysfunction induced by methionine. Am J Cardiol 2001; 88:285-90.

57. Woo KS, Chook P, Lolin YI, Cheung AS, Chan LT, Sun YY, et al. Hyperhomocyst(e)inemia is a risk factor for arterial endothelial dysfunction in humans. Circulation 1997; 96:2542-4.

58. Tawakol A, Omland T, Gerhard M, Wu JT, Creager MA. Hyperhomocyst(e)inemia is associated with impaired endothelium-dependent vasodilation in humans. Circulation 1997; 95:1119-21.

59. Holven KB, Holm T, Aukrust P, Christensen B, Kjekshus J, Andreassen AK, et al. Effect of folic acid treatment on endothelium-dependent vasodilation and nitric oxide-derived end products in hyperhomocysteinemic subjects. Am J Med 2001; 110:536-42.

60. Nappo F, De Rosa N, Marfella R, De Lucia D, Ingrosso D, Perna AF, et al. Impairment of endothelial functions by acute hyperhomocysteinemia and reversal by antioxidant vitamins. J Am Med Assoc 1999; 281:2113-8.

61. Clarke R, Armitage J. Vitamin supplements and cardiovascular risk: review of the randomized trials of homocysteine-lowering vitamin supplements. Semin Thromb Hemost 2000; 26:341-48.

62. Woo KS, Chook P, Lolin YI, Sanderson JE, Metreweli C, Celermajer DS. Folic acid improves arterial endothelial function in adults with hyperhomocystinemia. J Am Coll Cardiol 1999; 34:2002-6.

63. Chao CL, Chien KL, Lee YT. Effect of short-term vitamin (folic acid, vitamins B6 and B12) administration on endothelial dysfunction induced by post-methionine load hyperhomocysteinemia. Am J Cardiol 1999; 84:1359-61.

64. Bellamy MF, McDowell IF, Ramsey MW, Brownlee M, Newcombe RG, Lewis MJ. Oral folate enhances endothelial function in hyperhomocysteinaemic subjects. Eur J Clin Invest 1999; 29:659-62.

65. Vermeulen EG, Stehouwer CD, Twisk JW, van den Berg M, de Jong SC, Mackaay AJ, et al. Effect of homocysteinelowering treatment with folic acid plus vitamin B6 on progression of subclinical atherosclerosis: a randomised, placebo-controlled trial. Lancet 2000; 355:517-22.

66. van Guldener C, Stehouwer CD. Homocysteine-lowering treatment: an overview. Expert Opin Pharmacother 2001; 2:1449-60.

67. Clarke R, Armitage J. Antioxidant vitamins and risk of cardiovascular disease. Review of large-scale randomised trials. Cardiovasc Drugs Ther 2002; 16:411-5.

68. Boaz M, Smetana S, Weinstein T, Matas Z, Gafter U, laina A, et al. Secondary prevention with antioxidants of cardiovascular disease in endstage renal disease (SPACE): randomised placebo-controlled trial. Lancet 2000; 356:1213-8.

69. Tepel M, van der Giet M, Statz M, Jankowski J, Zidek W. The antioxidant acetylcysteine reduces cardiovascular events in patients with end-stage renal failure: a randomized, controlled trial. Circulation 2003; 107:992-5.

Received 13 May 2003, revised 21 July 2003, accepted 26 July 2003

Corresponding author: Priv.-Doz. Dr. med. Norbert Weiss, Medizinische Poliklinik - Innenstadt, Klinikum der Universität München, Pettenkoferstraße 8a, 80336 Munich, Germany Phone: +49-89-5160-3511, Fax: +49-89-5160-3559,

E-mail: Norbert.Weiss@med.uni-muenchen.de 